\title{
A population-based study on the association between the intake of soft drinks and periodontal disease in Taiwanese adults aged 35-44 years ( $\mathrm{KClS}$ no. 33)
}

\author{
Jean Ching-Yuan Fann ${ }^{1}$, Hongmin Lai ${ }^{2,3,4}$, Sherry Yueh-Hsia Chiu ${ }^{5}$, Amy Ming-Fang Yen ${ }^{4}$, \\ Sam Li-Sheng Chen ${ }^{4}$ and Hsiu-Hsi Chen ${ }^{6, *}$ \\ 'Department of Health Industry Management, College of Healthcare Management, Kainan University, Taoyuan, \\ Republic of China: ${ }^{2}$ QC Dental Clinic, Taipei, Republic of China: ${ }^{3}$ Department of Dentistry, National Yang-Ming \\ University, Taipei, Republic of China: ${ }^{4}$ School of Oral Hygiene, College of Oral Medicine, Taipei Medical University, \\ Taipei, Republic of China: ${ }^{5}$ Department of Health Care Management, College of Management, Chang Gung \\ University, Taoyuan, Republic of China: ${ }^{6}$ Division of Biostatistics, Graduate Institute of Epidemiology and Preventive \\ Medicine, College of Public Health, National Taiwan University, Room 533, No. 17 Hsuchow Road, Taipei 100, \\ Republic of China
}

Submitted 29 April 2015: Final revision received 9 July 2015: Accepted 6 August 2015: First published online 9 September 2015

\begin{abstract}
Objective: To elucidate the association between the intake of soft drinks and periodontal disease (PD) among Taiwanese middle-aged adults.

Design: The cross-sectional design was employed to assess a dose-response relationship between the intake of soft drinks and PD after controlling for relevant confounding factors, with adjusted odds ratios obtained from a multivariate logistic regression model.

Setting: Keelung Community-based Integrated Screening (KCIS) programme, Keelung, Taiwan.

Subjects: Participants ( $n 10$ 213) aged 35-44 years who had undergone oral checks for PD between 2005 and 2009.

Results: A dose-response relationship between the intake of soft drinks and elevated risk for PD defined by community periodontal index $\geq 3$ (the current status of PD) was noted ( $P=0.02$ by trend test). Compared with infrequent intake of soft drinks ( $\leq 2$ times/week), the adjusted OR increased from 1.05 (95\% CI 0.92 , 1.20) for the frequency of 3-4 times/week to 1.17 (95\% CI 1.03, 1.34) for the frequency of $\geq 5$ times/week. A similar trend $(P<0.01)$ was also observed for PD defined by loss of attachment $\geq 1$ (representing the long-term cumulative gum damage due to PD).

Conclusions: A dose-response relationship between the intake frequency of soft drinks and PD was observed in Taiwanese middle-aged adults. Such evidence could be used in health promotion to support reductions in soft drink intake.
\end{abstract}

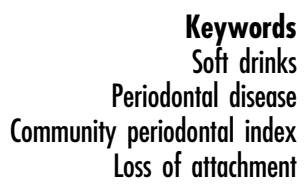

Keywords Periodontal disease Loss of attachment
It is well documented that the ingredients in soft drinks contribute to inflammation-related disorders such as insulin insensitivity and metabolic defects ${ }^{(1,2)}$. For instance, glucose-containing carbonated soft drinks increase carbonyl stress burden ${ }^{(3)}$, which, in turn, may result in a decrease in antioxidant concentration in oral saliva $^{(4)}$ and enhance oxidative nitration in association with the inflammatory reaction ${ }^{(5)}$.

From the biological viewpoint, the inflammatory reaction caused by such oxidative stress is highly associated with systemic diseases, such as metabolic syndrome, diabetes, hypertension, asthma and periodontal disease $(\mathrm{PD})^{(6-16)}$. Oxidative stress ${ }^{(2,3,6,8,9,13-15)}$ pertaining to PD may be mediated through advanced glycation end-products that are created through non-enzymatic pathways from monosaccharide substances, dicarbonyls originating from the Maillard reaction, sugar self-oxidation and other molecular pathways ${ }^{(16,17)}$.

Several studies show a link between soft drinks and systemic disease ${ }^{(18,19)}$, but the specific association between the intake of soft drinks and PD has not been investigated yet. From the aspect of epidemiology, it is therefore of interest to assess the association between the intake of soft drinks and PD through a large-scale 
epidemiological study. The main difficulty of conducting such an epidemiological study is that the main consumers of soft drinks are children and young adults, but severe PD is most prevalent in the elderly. The dietary habits observed in the elderly may be altered due to physical function degradation such as severe tooth loss. To shed light on the impact of the intake of certain nutrients on the development of PD, it may not be appropriate to target the elderly. Another reason for not aiming at the elderly is that the WHO has recommended monitoring periodontal conditions in individuals aged $35-44$ years $^{(20)}$ for early detection of PD.

A community-based PD screening project, one of the components of the Keelung Community-based Integrated Screening (KCIS) programme ${ }^{(21)}$, was initiated in 2003 and lasted until 2009. The assessment of PD using the community periodontal index (CPI) and loss of attachment (LA) measures was completed among individuals aged 35-44 years ${ }^{(22)}$. Because these community-based data also included information on sociodemographic variables (including age, sex and education level), dietary factors (including the intake frequencies of soft drinks, fruits and others), lifestyle factors (including cigarette smoking and teeth-brushing) and variables related to the inflammatory reaction (such as BMI, fasting plasma glucose and white blood cell level), we could assess the association between the intake frequency of soft drinks and the risk for PD making allowance for these established risk factors.

By using these community-based data focusing on a middle-aged population-based cohort, we sought to test a dose-response relationship between the frequency of the intake of soft drinks and PD measured by both PD indices (CPI and LA) after adjusting for other confounding factors.

\section{Materials and methods}

\section{Data source}

A dental check-up for PD in 2003 was included in the KCIS programme, which is a large population- and communitybased screening programme in Keelung, the northernmost city of Taiwan. The KCIS programme was a screening project to detect five types of neoplasm (cervical, breast, colorectal, oral and hepatocellular) and three chronic diseases (hypertension, diabetes and hyperlipidaemia). The KCIS programme was initiated in 1999 and details about its implementation are described in full elsewhere $^{(21)}$. All of the KCIS participants had signed informed consent. The KCIS programme was approved by the local health committee of the Keelung health authority, reviewed by the Ethics Committee of Chang Gung Memorial Hospital, and finally later approved by the Institutional Review Board (issued number 103-3920B).

A total of 10213 participants among 12208 invitees aged 35-44 years were enrolled to assess the severity of PD measured by the CPI and LA. The participation rate was $83.7 \%$. We only used the most recent and accessible data from 2005 to 2009 , because some questions related to dietary behaviour in the questionnaire were revised. We used the result of the first dental check-up in the following analysis.

\section{Measurement of community periodontal index and loss of attachment}

The present study used two types of measurements, the CPI and the LA, to assess PD. The former shows the current status of PD and the latter reflects the long-term cumulative gum damage due to PD. The screening procedure for PD was described in detail previously ${ }^{(22)}$. In brief, the CPI was assessed using a purpose-built CPI (or WHO) probe. This tool has a $0.5 \mathrm{~mm}$ diameter ball at its tip, a black band between 3.5 and $5.5 \mathrm{~mm}$, and coloured rings at 8.5 and $11.5 \mathrm{~mm}$ from the tip. The scores of CPI reflecting current periodontal status are as follows: 0 for healthy periodontium; 1 for gingival bleeding; 2 for calculus; 3 for a $4-5 \mathrm{~mm}$ periodontal pocket; and 4 for a $6 \mathrm{~mm}$ or deeper periodontal pocket. LA was assessed using the cementoenamel junction as the reference point for measuring the extent of attachment loss with scores listed as follows: 0 for $0-3 \mathrm{~mm}$; 1 for $4-5 \mathrm{~mm}$; 2 for $6-8 \mathrm{~mm}$; 3 for 9-11 $\mathrm{mm}$; and 4 for $12 \mathrm{~mm}$.

The mouth was divided into sextants, and the highest of the component scores for each sextant was taken to represent the overall sextant score. The highest of the sextant scores for each individual was selected to be representative of his/her overall PD status. All of the thirtyfive dentists included in the programme had been trained by a senior periodontist (the second author of the present study). The calibration for both CPI and LA was checked by having a number of dentists perform repeated assessments on the same twenty-five individuals. The weighted kappa values for intra-examiner variability were 0.55-0.61 for CPI and $0 \cdot 67-0.80$ for LA, indicating a moderate to good agreement between dentists. The equivalent figures for inter-examiner variability were $0.42-0.44$ for CPI and $0.41-0.57$ for LA, which again indicate moderate agreement $^{(22)}$.

\section{Measurement of explanatory factors}

Information on demographic characteristics, education level, lifestyle, dietary habits and medical history was collected through face-to-face interview using a structured questionnaire administered by public health nurses or trained volunteers. For biochemical variables, $12 \mathrm{~h}$ fasting blood samples were drawn at recruitment. Fasting plasma glucose and white blood cell levels were derived from a blood sample after at least an $8 \mathrm{~h}$ fast. Hyperglycaemia included impaired fasting glucose and diabetes. The former was defined as having fasting plasma glucose level $\geq 100 \mathrm{mg} / \mathrm{dl}$ but $<126 \mathrm{mg} / \mathrm{dl}$, and the latter was defined as fasting plasma glucose $\geq 126 \mathrm{mg} / \mathrm{dl}$ or having a history of diabetes. The question for the intake of soft drinks was 
'How many times have you had the intake of soft drinks (including carbonated beverage, cola, milk tea, and juice or asparagus juice) per week over the past half a year?' The frequency of the intake of soft drinks was classified into $\leq 2,3-4$ or $\geq 5$ times/week. The frequency of intake of fruits was classified into $\leq 2,3-4$ or $\geq 5$ times/week. Cigarette smoking was classified as ever having smoked or never having smoked. The former included current smokers and people who had quit smoking. Having the habit of brushing one's teeth was defined as brushing teeth both day and night. Height and weight were also collected, and BMI was calculated as weight/height ${ }^{2}$.

\section{Statistical analysis}

The associations between putative risk factors and PD were assessed using a logistic regression model. The estimates of crude and adjusted odds ratios regarding the associations between the intake of soft drinks and PD according to the two indices, $\mathrm{CPI} \geq 3$ and $\mathrm{LA} \geq 1$, were obtained from a univariate analysis and a multivariate analysis with adjustment for other covariates, respectively. The statistical significance of each variable was tested by the likelihood ratio test. The original classification of soft drink consumption was five categories, including none or seldom, 1-2 times/week, 3-4 times/week, 5-6 times/week and $\geq 7$ times/week. The descriptive results showed that these five levels could be reduced to three according the distribution of PD prevalence and also considering the sparse numbers in the two tails of the distribution of soft drink consumption. By combining none or seldom with 1-2 times/week, and also 5-6 times/week with $\geq 7$ times/ week, three levels were used as follows: $\leq 2$ times/week (including none or seldom, 1-2 times/week), 3-4 times/ week and $\geq 5$ times/week (including 5-6 times/week and $\geq 7$ times/week). A trend test was employed to assess whether there was a dose-response relationship between the frequency of the intake of soft drinks treated as an ordinal variable ( 1 for $\leq 2$ times/week; 2 for $3-4$ times/ week; 3 for $\geq 5$ times/week) and the risk for PD. Missing values were excluded from the analysis. The number of missing values based on information from Table 1 was 191 , about $2 \%$ (191/10 213), for the intake of soft drinks.

The statistical significance level was set at $P<0 \cdot 05$. All statistical analyses were conducted using the statistical software package SAS version $9 \cdot 2$.

\section{Results}

\section{Frequency of covariates by periodontal disease}

Table 1 shows the prevalence of CPI and LA by the intake of soft drinks and other explanatory factors. The prevalence of PD increased with the intake frequency of soft drinks, regardless of whether the analysis used CPI $\geq 3$ or $\mathrm{LA} \geq 1$ as the outcome. A higher prevalence was also found in the older age group, males, those with lower education level, ever smokers, those with irregular teethbrushing, hyperglycaemia, elevated white blood cell level $(>10000 / \mu \mathrm{l})$ and less intake of fruits.

\section{Association between the intake of soft drinks and periodontal disease (defined as community periodontal index $\geq 3$ )}

Table 2 shows the associations of the intake of soft drinks and other variables with PD (defined as CPI $\geq 3$ ). Compared with infrequent intake of soft drinks ( $\leq 2$ times) week), the crude odds indicating the elevated risk for PD resulting from increasing frequency of soft drink intake were $10 \%(\mathrm{OR}=1 \cdot 10 ; 95 \% \mathrm{CI} 0.97,1.25)$ for 3-4 times/ week and $33 \%(\mathrm{OR}=1.33 ; 95 \%$ CI $1.17,1.51)$ for $\geq 5$ times/week, respectively, in the univariate analysis ( $P<0.01$ by trend test). The corresponding adjusted OR in the multivariate analysis increased from 1.05 (95\% CI 0.92, 1.20) for the frequency of 3-4 times/week to $1 \cdot 17$ (95\% CI $1 \cdot 03,1.34)$ for $\geq 5$ times/week compared with infrequent intake of soft drinks ( $\leq 2$ times/week; $P=0.02$ by trend test).

\section{Association between the intake of soft drinks and periodontal disease (defined as loss of attachment $\geq 1$ )}

Table 3 shows the associations with the intake of soft drinks and other variables responsible for the risk for PD (defined as $L A \geq 1$ ). Compared with the infrequent intake of soft drinks ( $\leq 2$ times/week), the crude odds of the intake of soft drinks 3-4 times/week and $\geq 5$ times/week led to $18 \%(\mathrm{OR}=1.18 ; 95 \% \mathrm{CI} 1.05,1.33)$ and $24 \%$ $(\mathrm{OR}=1.24 ; 95 \%$ CI $1.10,1.40)$ elevated risk for $\mathrm{PD}$, respectively, in the univariate analysis $(P<0.01$ by trend test). After adjusting for other covariates, the corresponding adjusted $\mathrm{OR}$ in the multivariate analysis were 1.17 (95\% CI 1.03, 1.32) and 1.14 (95\% CI 1.01, 1.29), respectively $(P<0 \cdot 01$ by trend test).

\section{Other significant factors related to periodontal disease}

Table 2 shows other relevant factors associated with the risk for PD (defined as CPI $\geq 3$ ). Only those variables with statistically significant associations were kept in the final multivariate analysis. An incremental increase in age of one year led to a $5 \%$ elevated risk for PD. Males were more susceptible to PD than females by $51 \%$. People with a lower education level were more likely to have PD. There was a 30\% increase for those with 6-12 years of education and a $9 \%$ increase for $<6$ years of education compared with those with $\geq 12$ years of education $(P<0 \cdot 01)$. Those who had smoked were at increased risk for PD compared with those who had never smoked by $21 \%$. Regular teeth-brushing reduced the risk for PD by $29 \%$. Increased risk for PD was noted for those with 
Table 1 Prevalence of periodontal disease defined by CPI and LA score among Taiwanese adults aged 35-44 years, Keelung Community-based Integrated Screening programme, 2005-2009

\begin{tabular}{|c|c|c|c|c|c|}
\hline \multirow[b]{2}{*}{ Variable/level } & \multirow[b]{2}{*}{ Total } & \multicolumn{2}{|c|}{$\mathrm{CPI} \geq 3$} & \multicolumn{2}{|c|}{$L A \geq 1$} \\
\hline & & $n$ & Prevalence (\%) & $n$ & Prevalence (\%) \\
\hline \multicolumn{6}{|l|}{ Intake of soft drinks } \\
\hline$\leq 2$ times/week & 7370 & 1896 & 26 & 2952 & 40 \\
\hline 3-4 times/week & 1347 & 372 & 28 & 594 & 44 \\
\hline$\geq 5$ times/week & 1305 & 412 & 32 & 592 & 45 \\
\hline Subtotal & 10022 & 2680 & 27 & 4138 & 41 \\
\hline \multicolumn{6}{|l|}{ Age group } \\
\hline $35-39$ years & 5957 & 1473 & 25 & 2238 & 38 \\
\hline 40-44 years & 4256 & 1247 & 29 & 1980 & 47 \\
\hline Subtotal & 10213 & 2720 & 27 & 4218 & 41 \\
\hline \multicolumn{6}{|l|}{ Sex } \\
\hline Female & 6355 & 1419 & 22 & 2326 & 37 \\
\hline Male & 3858 & 1301 & 34 & 1892 & 49 \\
\hline Subtotal & 10213 & 2720 & 27 & 4218 & 41 \\
\hline \multicolumn{6}{|l|}{ Education level } \\
\hline$\geq 12$ years & 4022 & 922 & 23 & 1512 & 38 \\
\hline $6-12$ years & 5886 & 1719 & 29 & 2554 & 43 \\
\hline$<6$ years & 305 & 79 & 26 & 152 & 50 \\
\hline Subtotal & 10213 & 2720 & 27 & 4218 & 41 \\
\hline \multicolumn{6}{|l|}{ Cigarette smoking } \\
\hline Never & 6914 & 1590 & 23 & 2600 & 38 \\
\hline Ever & 3267 & 1122 & 34 & 1599 & 49 \\
\hline Subtotal & 10181 & 2712 & 27 & 4199 & 41 \\
\hline \multicolumn{6}{|l|}{ Regular teeth-brushing } \\
\hline Without & 235 & 94 & 40 & 112 & 48 \\
\hline With & 9808 & 2593 & 26 & 4038 & 41 \\
\hline Subtotal & 10043 & 2687 & 27 & 4150 & 41 \\
\hline \multicolumn{6}{|l|}{ BMI } \\
\hline Underweight $\left(<18.5 \mathrm{~kg} / \mathrm{m}^{2}\right)$ & 438 & 119 & 27 & 174 & 40 \\
\hline Normal $\left(18.5-24.9 \mathrm{~kg} / \mathrm{m}^{2}\right)^{\prime}$ & 6335 & 1572 & 25 & 2467 & 39 \\
\hline Overweight $\left(25.0-29.9 \mathrm{~kg} / \mathrm{m}^{2}\right)$ & 2710 & 804 & 30 & 1232 & 45 \\
\hline Obesity $\left(\geq 30.0 \mathrm{~kg} / \mathrm{m}^{2}\right)$ & 678 & 214 & 32 & 312 & 46 \\
\hline Subtotal & 10161 & 2709 & 27 & 4185 & 41 \\
\hline \multicolumn{6}{|l|}{ Hyperglycaemia } \\
\hline Normal & 9052 & 2322 & 26 & 3676 & 41 \\
\hline IFG & 860 & 276 & 32 & 380 & 44 \\
\hline Diabetes & 252 & 105 & 42 & 132 & 52 \\
\hline Subtotal & 10164 & 2703 & 27 & 4188 & 41 \\
\hline \multicolumn{6}{|l|}{ WBC } \\
\hline$\leq 10000 / \mu l$ & 9739 & 2553 & 26 & 3962 & 41 \\
\hline$>10000 / \mu \mathrm{l}$ & 418 & 148 & 35 & 224 & 54 \\
\hline Subtotal & 10157 & 2701 & 27 & 4186 & 41 \\
\hline \multicolumn{6}{|l|}{ Intake of fruits } \\
\hline$\leq 2$ times/week & 789 & 275 & 35 & 363 & 46 \\
\hline 3-4 times/week & 5066 & 1447 & 29 & 2169 & 43 \\
\hline$\geq 5$ times/week & 4166 & 956 & 23 & 1605 & 39 \\
\hline Subtotal & 10021 & 2678 & 27 & 4137 & 41 \\
\hline
\end{tabular}

CPI, community periodontal index; LA, loss of attachment; IFG, impaired fasting glucose; WBC, white blood cell.

impaired fasting glucose by $19 \%$ and for those with type 2 diabetes by $72 \%$. The risk for PD was also elevated for higher white blood cell level by $26 \%$. There was no difference in the prevalence of PD between those consuming fruit $\leq 2$ times/week and those consuming it 3-4 times/week; however, the prevalence of PD was somewhat lower for people consuming fruit $\geq 5$ times/ week in the multivariate analysis.

Similar findings were noted for the LA outcome measure as shown in Table 3 but the effect sizes were smaller compared with the CPI outcome, except for age. Hyperglycaemia (including impaired fasting glucose and diabetes) was not statistically significant but as the $95 \%$ CI of the adjusted OR for diabetes compared with normal did not include 1 , we therefore kept this variable in the final multivariate model. Besides, teeth-brushing was not statistically significant (data not shown).

\section{Discussion}

\section{Impact of soft drinks on periodontal disease}

In the current study, we investigated the association between the intake of soft drinks and the risk for PD using two indices (CPI and LA) among Taiwanese middle-aged 
Table 2 Association between the intake of soft drinks and periodontal disease (defined as CPI $\geq 3$ ) among Taiwanese adults aged 35-44 years, Keelung Community-based Integrated Screening programme, 2005-2009

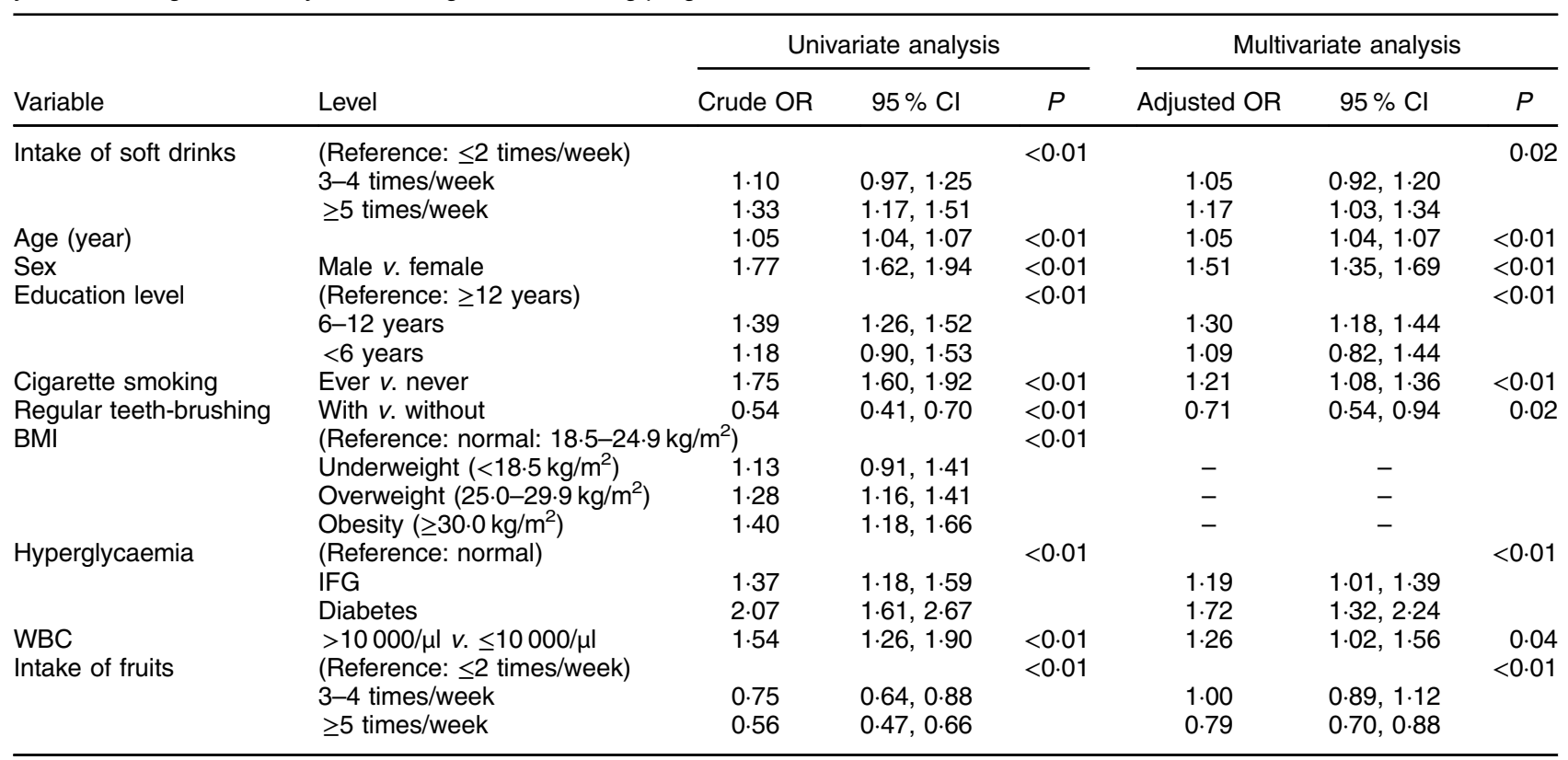

CPI, community periodontal index; WBC, white blood cell; IFG, impaired fasting glucose.

Table 3 Association between the intake of soft drinks and periodontal disease (defined as $L A \geq 1$ ) among Taiwanese adults aged 35-44 years, Keelung Community-based Integrated Screening programme, 2005-2009

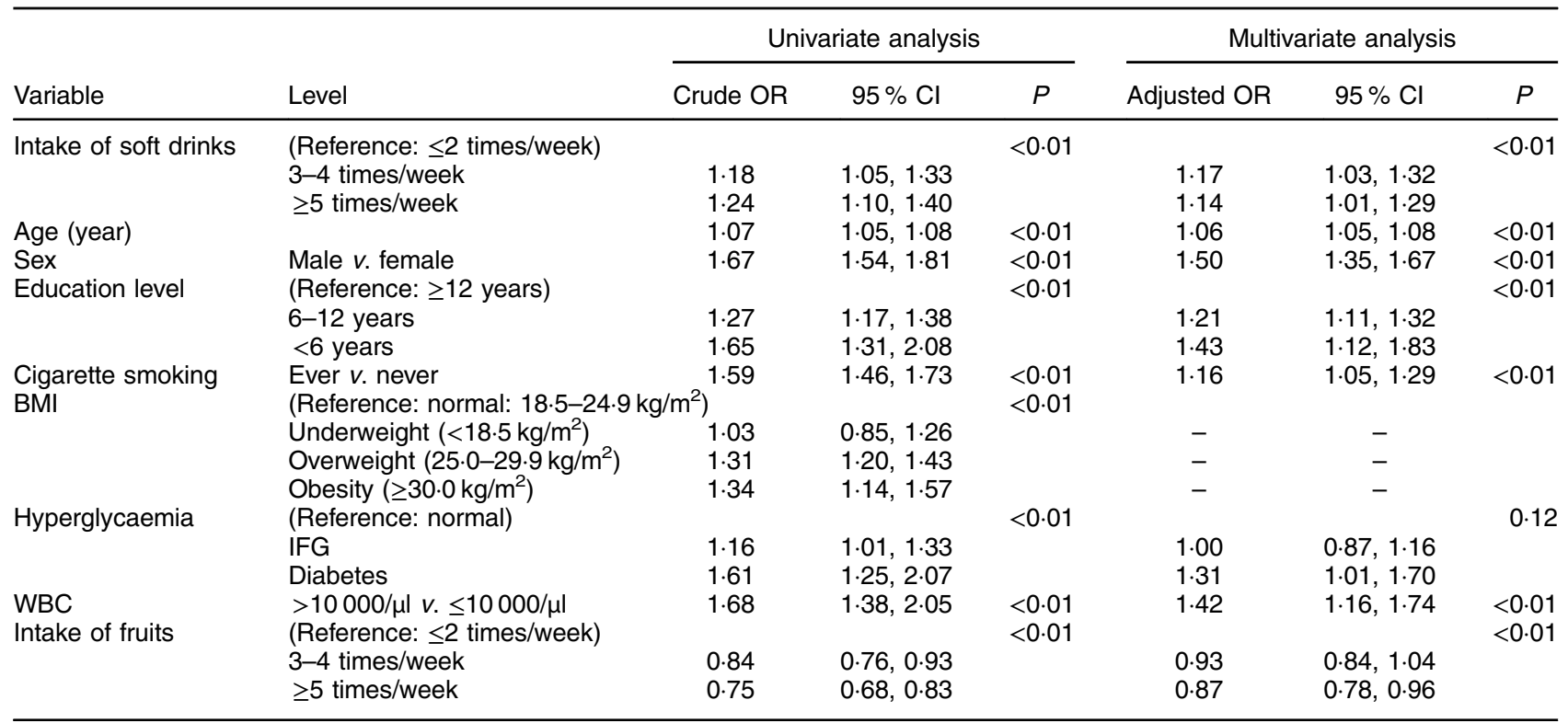

LA, loss of attachment; WBC, white blood cell; IFG, impaired fasting glucose.

adults based on a large population- and communitybased screening programme in Keelung City, the northernmost city of Taiwan. The dose-response relationship results support the fact that increasing soft drink intake was associated with the risk for PD, regardless of whether the CPI or LA index was used, after adjusting for hyperglycaemia and other relevant confounding factors, although the causal relationship still needs to be verified.

While the mechanism linking soft drink consumption and PD is not known, it is possible that oxidative stress $^{(6-8,4,23)}$ or bone mineralization ${ }^{(24-28)}$, either alone or 
in combination, is involved. More data will be required to verify this.

\section{The influence of other confounding factors on periodontal disease}

Hyperglycaemia was the strongest risk factor for PD with outcome of $\mathrm{CPI} \geq 3$. The association with BMI was confounded by other covariates in the multivariate analysis. However, overweight remains a possible risk factor for systemic disease because adipocytokines, which are produced by fat cells, might modulate the balance between oxidant and antioxidant activities ${ }^{(29)}$. A previous study also found that overweight subjects with high consumption of sugar-sweetened foods and drinks had an increase in two inflammatory markers: haptoglobin and transferrin ${ }^{(29)}$.

Smoking was associated with PD in the present study. This finding supported the point proposed by Colombo et al. ${ }^{(30)}$ that oxidative stress caused by smoking would damage the oral cavity tissue. The association with teeth-brushing was significant when the CPI but not LA was the outcome. This finding implies that the association between frequent intake of soft drinks and the current status of PD, indicated by the CPI, may be amenable to treatment, but the long-term, cumulative, adverse effect indicated by the LA measure may not.

Although we had also collected data on other dietary items including the intakes of vegetables, meat, coffee, milk and tea in this community-based cohort, these dietary factors are not shown partly because only the intake of fruits was still associated with PD in the multivariate analysis and partly because the intake of fruits was more relevant owing to their high sugar content compared with other foods. The intake of fruits showed a negative association with PD but it did not confound the effect of soft drinks on PD. In-depth discussions on these non-significant dietary items are beyond the scope the current study.

\section{Application to bealth education and policy}

Consistent with the previous evidence that the negative health outcomes of soft drink consumption play an important role not only in obesity, diabetes and $\operatorname{CVD}^{(17,18,31,32)}$ but also in oral health ${ }^{(33)}$, the current study further demonstrated a significant dose-response relationship between the intake of soft drinks and PD among Taiwanese middle-aged adults.

These epidemiological findings are very meaningful for the health of Taiwanese middle-aged adults who are frequent consumers of soft drinks as they are not aware of such a threat. Therefore, the intake of soft drinks should be reduced through specific health promotion programmes to prevent the progression rates of those related systemic diseases.

Accordingly, appropriate public health strategies that target individual, environmental and policy levels are recommended to increase public awareness of the negative impact of soft drink consumption on health.

\section{Methodological considerations}

There are several strengths of the present study. In addition to a large population-based sample, the study was targeted at middle-aged adults. As mentioned before, dietary habits may be altered because of systemic diseases when ageing. Collecting biomarkers, lifestyle characteristics and disease history simultaneously renders the elimination of confounding factors possible. More importantly, two indices, the CPI reflecting current status and the LA reflecting cumulative damage, were measured.

There are also several limitations. First, we used the most common cut-off point of CPI $\geq 3$ to classify PD. When treating the CPI as an ordinal outcome with 0 to 4 , the association between the intake of soft drinks and CPI was still statistically significant in the univariate analysis with an ordinal logistic regression model, similar to the results from a binary logistic regression model with the dichotomized CPI with $<3$ and $\geq 3$, with OR of $1 \cdot 10$ and 1.33 for the intake of soft drinks 3-4 times/week and $\geq 5$ times/week, respectively. However, the proportional odds assumption was violated when adjusting for other covariates in the multivariate ordinal logistic regression model treating CPI as an ordinal outcome. Therefore, we reported the results based on the dichotomized classification for CPI. Second, there is no information on whether soft drinks were sweetened with sugar or otherwise and this would have to be one of the possible reasons for an association between soft drinks and various adverse outcomes. In addition, the possibility exists that soft drink consumption is associated with other dietary patterns that contribute to PD but we do not have the data to explore. Third, the current study was based on an epidemiological study and lacked direct evidence, such as the concentration of inflammatory biomarkers, to support whether the association of soft drink intake with PD was mediated through the pathway of increasing the inflammatory reaction. Only the white blood cell level can be considered as an inflammatory biomarker in our study. Having more inflammatory biomarker data would help us determine whether the association observed was mediated through inflammation. Some variables such as hyperglycaemia and BMI have been associated with inflammation in other studies ${ }^{(6,8,13-16,23,29)}$. The fact that the soft drink-PD relationship persisted after adjustment for these variables may in some part be due to them not accounting completely for inflammation, although there may well be other mechanisms as well. This finding may suggest there is another pathway leading to PD that is independent of the inflammatory reaction.

Regarding the representativeness of our finding, it is unsure whether the study sample can be representative of the general public aged 35-44 years in Taiwan as we do not have the nationwide population data. However, the results are representative of the underlying residents in Keelung City as this is a community-based survey through 
a community-based screening that almost covers the entire eligible study population in the whole city.

\section{Conclusions}

A dose-response relationship between the frequency of the intake of soft drinks and PD was observed in Taiwanese middle-aged adults. Such evidence could be used in health promotion to support reductions in soft drink intake.

\section{Acknowledgements}

Acknowledgements: The authors thank all of the personnel of the Health Bureau of Keelung City, Keelung City, Taiwan for contributing to the KCIS programme. This article was identified as KCIS no. 33. Financial support: This research received no specific grant from any funding agency in the public, commercial or not-for-profit sectors. Conflict of interest: None. Authorship: H.-H.C., J.C.-Y.F. and H.L. designed the research; J.C.-Y.F., S.Y.-H.C., A.M.-F.Y. and S.L.-S.C. conducted the research; H.L. provided essential materials; J.C.-Y.F., S.Y.-H.C., A.M.-F.Y. and S.L.-S.C. analysed the data; J.C.-Y.F. and H.-H.C. wrote the paper; H.-H.C. had primary responsibility for final content. All authors read and approved the final manuscript. Ethics of buman subject participation: The KCIS programme was approved by the local health committee of the Keelung health authority, reviewed by the Ethics Committee of Chang Gung Memorial Hospital, and approved by the Institutional Review Board (issued number 103-3920B). All KCIS participants provided signed informed consent.

\section{References}

1. Gaby AR (2005) Adverse effects of dietary fructose. Altern Med Rev 10, 294-306.

2. Schulze MB, Hoffmann K, Manson JE et al. (2005) Dietary pattern, inflammation, and incidence of type 2 diabetes in women. Am J Clin Nutr 82, 675-684.

3. Nakayama K, Nakayama M, Terawaki H et al. (2009) Carbonated soft drinks and carbonyl stress burden.J Toxicol Sci 34, 699-702.

4. Sculley DV \& Langley-Evans SC (2003) Periodontal disease is associated with lower antioxidant capacity in whole saliva and evidence of increased protein oxidation. Clin Sci (Lond) 105, 167-172.

5. Takahama U, Imamura H \& Hirota S (2009) Nitration of the salivary component 4-hydroxyphenylacetic acid in the human oral cavity: enhancement of nitration under acidic conditions. Eur J Oral Sci 117, 555-562.

6. Southerland JH, Taylor GW, Moss K et al. (2006) Commonality in chronic inflammatory diseases: periodontitis, diabetes, and coronary artery disease. Periodontol 2000 40, 130-143.

7. Hujoel P (2009) Dietary carbohydrates and dental-systemic diseases. J Dent Res 88, 490-502.
8. Preshaw PM, Alba AL, Herrera D et al. (2012) Periodontitis and diabetes: a two-way relationship. Diabetologia $\mathbf{5 5}$, 21-31.

9. D'Aiuto F, Nibali L, Parkar M et al. (2010) Oxidative stress, systemic inflammation, and severe periodontitis. J Dent Res 89, 1241-1246.

10. Tamaki N, Tomofuji T, Ekuni D et al. (2011) Periodontal treatment decreases plasma oxidized LDL level and oxidative stress. Clin Oral Investig 15, 953-958.

11. Sahiner UM, Birben E, Erzurum S et al. (2011) Oxidative stress in asthma. World Allergy Organ J 4, 151-158.

12. Pendyala G, Thomas B \& Joshi SR (2013) Evaluation of total antioxidant capacity of saliva in type 2 diabetic patients with and without periodontal disease: a case-control study. $N$ Am J Med Sci 5, 51-57.

13. Bullon P, Morillo JM, Ramirez-Tortosa MC et al. (2009) Metabolic syndrome and periodontitis: is oxidative stress a common link? J Dent Res $\mathbf{8 8}, 503-518$.

14. Ritchie CS (2009) Mechanistic links between type 2 diabetes and periodontitis. J Dent 37, issue 8, S578-S579.

15. Allen EM, Matthews JB, O'Connor R et al. (2009) Periodontitis and type 2 diabetes: is oxidative stress the mechanistic link? Scott Med J 54, 41-47.

16. Pietropaoli D, Monaco A, Del Pinto R et al. (2012) Advanced glycation end products: possible link between metabolic syndrome and periodontal diseases. Int J Immunopathol Pharmacol 25, 9-17.

17. Howard BV \& Wylie-Rosett J (2002) Sugar and cardiovascular disease: a statement for healthcare professionals from the Committee on Nutrition of the Council on Nutrition, Physical Activity, and Metabolism of the American Heart Association. Circulation 106, 523-527.

18. Eshak ES, Iso H, Kokubo Y et al. (2012) Soft drink intake in relation to incident ischemic heart disease, stroke, and stroke subtypes in Japanese men and women: the Japan Public Health Centre-based study cohort I. Am J Clin Nutr 96, 1390-1397.

19. Shi Z, Dal Grande E, Taylor AW et al. (2012) Association between soft drink consumption and asthma and chronic obstructive pulmonary disease among adults in Australia. Respirology 17, 363-369.

20. World Health Organization (1997) Oral Health Survey. Basic Methods, 4th ed. Geneva: WHO.

21. Chen TH, Chiu YH, Luh DL et al. (2004) Community-based multiple screening model: design, implementation, and analysis of 42,387 participants. Cancer 100, 1734-1743.

22. Lai H, Lo MT, Wang PE et al. (2007) A community-based epidemiological study of periodontal disease in Keelung, Taiwan: a model from Keelung community-based integrated screening program (KCIS no. 18). J Clin Periodontol 34, 851-859.

23. Marchetti E, Monaco A, Procaccini L et al. (2012) Periodontal disease: the influence of metabolic syndrome. Nutr Metab (Lond) 9, 88.

24. Inagaki K, Kurosu Y, Yoshinari N et al. (2005) Efficacy of periodontal disease and tooth loss to screen for low bone mineral density in Japanese women. Calcif Tissue Int 77, 9-14.

25. McGartland C, Robson PJ, Murray L et al. (2003) Carbonated soft drink consumption and bone mineral density in adolescence: the Northern Ireland Young Hearts project. J Bone Miner Res 18, 563-569.

26. Tucker KL, Morita K, Qiao N et al. (2006) Colas, but not other carbonated beverages, are associated with low bone mineral density in older women: the Framingham Osteoporosis Study. Am J Clin Nutr 84, 936-942.

27. Libuda L, Alexy U, Remer $\mathrm{T}$ et al. (2008) Association between long-term consumption of soft drinks and variables of bone modeling and remodeling in a sample of 
healthy German children and adolescents. Am J Clin Nutr 88, 1670-1677.

28. Esfahanian V, Shamami MS \& Shamami MS (2012) Relationship between osteoporosis and periodontal disease: review of the literature. J Dent (Tehran) 9, 256-264.

29. Sørensen LB, Raben A, Stender S et al. (2005) Effect of sucrose on inflammatory markers in overweight humans. Am J Clin Nutr 82, 421-427.

30. Colombo G, Dalle-Donne I, Orioli M et al. (2012) Oxidative damage in human gingival fibroblasts exposed to cigarette smoke. Free Radic Biol Med 52, 1584-1589.
31. Odegaard AO, Koh WP, Arakawa K et al. (2010) Soft drink and juice consumption and risk of physician-diagnosed incident type 2 diabetes: the Singapore Chinese Health Study. Am J Epidemiol 171, 701-708

32. Ogden CL, Kit BK, Carroll MD et al. (2011) Consumption of sugar drinks in the United States, 2005-2008. NCHS Data Brief issue 71, 1-8.

33. Tahmassebi JF, Duggal MS, Malik-Kotru G et al. (2006) Soft drinks and dental health: a review of the current literature. J Dent 34, 2-11. 